\title{
Baseline prostate-specific antigen levels following treatment with abiraterone acetate as a prognostic factor in castration-resistant prostate cancer
}

\author{
TASUKU HIROSHIGE ${ }^{1}$, YOSHIRO EGUCHI ${ }^{1}$, OSAMU YOSHIZUMI ${ }^{1}$, KATSUAKI CHIKUI $^{2}$, \\ HISAJI KUMAGAI ${ }^{3}$, YOSHIHIRO KAWAGUCHI ${ }^{4}$, REI ONISHI ${ }^{5}$, TOKUMASA HAYASHI ${ }^{6}$, \\ KOUTA WATANABE $^{7}$, TOMOTARO MITANI ${ }^{8}$, KOUJIRO SAITO $^{9}$ and TSUKASA IGAWA ${ }^{2}$ \\ ${ }^{1}$ Department of Urology, St. Maria Hospital, Kurume, Fukuoka 830-8543; ${ }^{2}$ Department of Urology, \\ Kurume University School of Medicine, Kurume, Fukuoka 830-0011; ${ }^{3}$ Department of Urology, \\ Yame General Hospital, Yame, Fukuoka 834-0034; ${ }^{4}$ Department of Urology, Chikugo City Hospital, Chikugo, \\ Fukuoka 833-0041; ${ }^{5}$ Department of Urology, Kurume General Hospital, Kurume, Fukuoka 830-0013; \\ ${ }^{6}$ Department of Urology, Kurume University Medical Center, Kurume, Fukuoka 839-0863; ${ }^{7}$ Department of Urology, \\ Takagi Hospital, Okawa, Fukuoka 831-0016; ${ }^{8}$ Department of Urology, Omuta City Hospital, Omuta, Fukuoka 836-8567; \\ ${ }^{9}$ Department of Urology, Saiseikai Omuta Hospital, Omuta, Fukuoka 837-0916, Japan
}

Received August 2, 2017; Accepted November 16, 2017

DOI: $10.3892 / 01.2018 .8263$

\begin{abstract}
The aim of the present study was to investigate the prognostic factors associated with progression-free survival (PFS) and overall survival (OS) times in patients with castration-resistant prostate cancer (CRPC) who received treatment with abiraterone acetate (AA) in routine clinical settings. A total of 93 patients treated with AA between September 2014 and February 2017 were selected and their medical records were analyzed retrospectively. The median PFS time of docetaxel (DTX)-naïve patients was 171 days, and that of post-DTX patients was 56 days. The OS time of DTX-naïve patients did not reach the median. The median OS time of post-DTX patients was 761 days. Multivariate analyses identified baseline prostate-specific antigen (PSA) level prior to treatment with AA and the PSA response rate as independent prognostic factors for PFS time, and baseline PSA prior to treatment with AA as the only independent prognostic factor for OS time. The results of the present study indicate that the baseline PSA level prior to treatment with AA is a notable prognostic factor in patients with CRPC.
\end{abstract}

Correspondence to: Dr Tasuku Hiroshige, Department of Urology, St. Maria Hospital, 422 Tsubukuhonmachi, Kurume, Fukuoka 830-8543, Japan

E-mail: tkkn19841220@yahoo.co.jp

Key words: baseline prostate-specific antigen, castration-resistant prostate cancer, abiraterone acetate

\section{Introduction}

Androgen deprivation therapy (ADT) has been widely used for advanced prostate cancer since Huggins and Hodges (1) first identified this therapy. Up to $80 \%$ of patients respond favorably to ADT; nevertheless, the therapy is not curative and the disease progresses to castration-resistant prostate cancer (CRPC) within 1-2 years of starting ADT $(2,3)$. Docetaxel (DTX) was discovered in 2004 and until recently has been the only agent demonstrated to provide a substantial survival benefit to patients with CRPC, despite the development of resistance (or intolerance) to this therapy and eventual disease progression $(4,5)$.

The treatment paradigm for CRPC had been altered markedly with the advent of a number of androgen receptor (AR)-pathway-targeted agents [including enzalutamide (ENZ) and abiraterone acetate (AA)] and new-generation chemotherapy [including cabazitaxel (CBZ)] (6-10). AA is an inhibitor of an androgen biosynthesis enzyme, cytochrome P450 17- $\alpha$ hydroxylase/17,20-lyase (CYP17A1), which is expressed in testicular, adrenal and prostate tumor tissues, explaining why CRPC tumor growth relies on androgen stimulation (6). AA suppresses androgen synthesis in the testis, adrenal gland and prostate tumor tissues and decreases circulating testosterone levels (11). In the COU-AA-301 clinical trial (6), treatment with AA alongside prednisone substantially increased the median overall survival (OS) compared with placebo in patients with metastatic CRPC (mCRPC) who had previously been treated with DTX. In the COU-AA-302 clinical trial (7), treatment with AA in addition to prednisone significantly increased median OS compared with placebo in patients with metastatic DTX-naïve CRPC.

In Japan, AA is now widely used for patients with CRPC since its approval in 2014 (12). However, few studies of 
Japanese patients with CRPC treated with AA have been reported. There is notable interest in confirming whether the efficacy of AA demonstrated in trial settings is reproducible in routine clinical practice, given the potential differences in the selection of patients, ethnic differences and other factors in day-to-day practice. AA is effective for DTX-naïve and post-DTX treated patients with CRPC, yet the efficacy of AA varies substantially between individuals (13). In addition, there is cross-resistance among DTX, AA and ENZ (a second-generation anti-androgen), and the sequence in which these drugs are administered to the patient affects the efficacy of treatment $(14,15)$. Therefore, the identification of biomarkers is necessary in order to predict the effect of AA. In the present study, a collected database on patients with CRPC who started AA treatment were retrospectively analyzed, with the aim of evaluating outcomes in clinical practice in Japan and identifying the prognostic factors for progression-free survival (PFS) and OS in these patients.

\section{Patients and methods}

Patients and treatment. The present study was performed by the evaluation of medical records of 93 consecutive Japanese patients with CRPC (median age, 74 years; range, 55-93 years) who received AA $(1,000 \mathrm{mg}$ orally once daily at least $1 \mathrm{~h}$ before or $2 \mathrm{~h}$ after a meal, alongside prednisone $10 \mathrm{mg}$ daily) at 9 institutions (St. Maria Hospital, Kurume University School of Medicine, Yame General Hospital, Chikugo City Hospital, Kurume General Hospital, Kurume University Medical Center, Takagi Hospital, Omuta City Hospital and Saiseikai Omuta Hospital; all Fukuoka, Japan) between September 2014 and February 2017. A total of 93 patients who underwent continuous AA treatment for $>1$ month were included to measure efficiency. The present study was approved by the Research Ethics Review Committee of St. Maria Hospital (Kurume, Japan), Kurume University School of Medicine (Kurume, Japan), Yame General Hospital (Yame, Japan), Chikugo City Hospital (Chikugo, Japan), Kurume General Hospital (Kurume, Japan), Kurume University Medical Center (Kurume, Japan), Takagi Hospital (Okawa, Japan), Omuta City Hospital (Omuta, Japan) and Saiseikai Omuta Hospital (Omuta, Japan). The requirement for informed consent was waived due to the retrospective nature of the study.

Prostate-specific antigen (PSA) levels, full blood counts and routine biochemical data were measured at least every 1-3 months, whereas radiologic examinations (computed tomography/bone scans) were performed according to the discretion of treating physicians. AA was discontinued subsequent to the confirmation of disease progression if no earlier intolerable adverse events occurred, including cardiac disorder and liver dysfunction. Disease progression during AA treatment was identified using a combination of PSA and radiographic progression. PSA progression was defined according to the definition specified by the Prostate Cancer Working Group 2 (16). Radiographic progression was defined using the Response Evaluation Criteria in Solid Tumors (17). PSA response to AA was defined as a decline in PSA of $\geq 50 \%$ from the PSA value immediately prior to the introduction of AA. Patients were stratified using potential predictors of outcome, including the following: Age, initial PSA level,
Gleason score (18), previous prostatectomy or curative radiotherapy, PSA nadir level during initial ADT, duration from ADT initiation to PSA nadir, duration of initial ADT, number of previous anti-androgen agents, the presence of visceral, lymph node and bone metastases, previous treatment with estrogen preparations, baseline PSA prior to treatment with AA and PSA response rate during treatment with AA. Cut-offs were determined using the median values of all the data available for each factor.

Statistical analysis. All continuous variables were expressed as median and ranges (standard deviation). Patient characteristics were compared using a Mann-Whitney U test or Fisher's exact test. Time-to-event distributions were estimated using Kaplan-Meier curves and significance was assessed using a log-rank test. Univariate and multivariate analyses were performed using Cox proportional hazards models. PFS was defined as the period between the initial administration of AA and the time of diagnosis of disease progression. OS was calculated from the initiation of CRPC treatment until mortality from any cause. All analyses were performed using EZR software version 1.27 (Saitama Medical Center, Jichi Medical University, Saitama, Japan), which is a graphical user interface for $\mathrm{R}$ and a modified version of $\mathrm{R}$ commander with added statistical functions (19). $\mathrm{P}<0.05$ was considered to indicate a statistically significant difference.

\section{Results}

Characteristics of the patients. Among the 93 patients (Table I), 78 were DTX-naïve and 15 had a post-DTX status. The median age was 74 years (range, 55-93) and the post-DTX group was significantly younger $(\mathrm{P}=0.0080)$. Radical prostatectomy or radiation therapy had been performed in 17 patients in the DTX-naïve group and 3 patients in the post-DTX group. The median initial PSA at the time of prostate cancer diagnosis was $92.4 \mathrm{ng} / \mathrm{ml}$ (range, 3.13-12,534 ng/ml). The median progression time to CRPC was 517 days (range, 118-5,944) for all patients and the median lowest level of PSA during initial ADT was $0.4045 \mathrm{ng} / \mathrm{ml}$ (range, 0.01-352 ng/ml). These data did not differ significantly between the DTX-naïve and post-DTX groups. Significantly more patients in the post-DTX group had received estrogen preparations $(\mathrm{P}=0.0172)$ and ENZ $(\mathrm{P}=0.0002)$ compared with the DTX-naïve group (Table I).

Radiographically confirmed metastases in bone, lymph nodes and visceral organs were present in 67.7, 18.3 and $10.8 \%$ of all patients, respectively. The rate of bone metastasis was significantly higher in the post-DTX group $(\mathrm{P}=0.0315)$ compared with the DTX-naïve group. The median baseline PSA prior to treatment with AA was $9.855 \mathrm{ng} / \mathrm{ml}$ (range, 0.06-853.2 ng/ml). There was no significant difference identified in the number of anti-androgen treatments, rates of lymph node and visceral metastases, and baseline PSA prior to treatment with AA between the DTX-naïve and post-DTX groups.

PSA response. Maximum reduction in serum PSA level during treatment with AA is presented in Fig. 1. The PSA response rate to AA in the DTX-naïve group was higher compared with 
Table I. Patient characteristics.

\begin{tabular}{|c|c|c|c|c|}
\hline Clinicopathological factor & $\begin{array}{l}\text { All patients } \\
\quad(\mathrm{n}=93)\end{array}$ & $\begin{array}{l}\text { DTX-naive } \\
\quad(\mathrm{n}=78)\end{array}$ & $\begin{array}{l}\text { Post-DTX } \\
(\mathrm{n}=15)\end{array}$ & P-value \\
\hline Median age, years (range) & $74(55-93)$ & $75(55-93)$ & $71(56-81)$ & 0.008 \\
\hline Gleason score & & & & 0.547 \\
\hline$\leq 8, \mathrm{n}$ & 31 & 25 & 6 & \\
\hline$\geq 9, \mathrm{n}$ & 50 & 43 & 7 & \\
\hline Unknown, n & 12 & 10 & 2 & \\
\hline Median iPSA, ng/ml (range) & $92.40(3.13-12,534)$ & $115.90(3.13-12,534)$ & $43.90(3.20-3,370)$ & 0.704 \\
\hline Radical therapy & & & & 0.239 \\
\hline None, $\mathrm{n}$ & 73 & 61 & 12 & \\
\hline Prostatectomy, n & 11 & 8 & 3 & \\
\hline Radiation, $\mathrm{n}$ & 9 & 9 & 0 & \\
\hline Median progression time to CRPC, days (range) & $517(118-5,944)$ & $570(119-5,944)$ & $317(118-1,830)$ & 0.121 \\
\hline Median PSA nadir during initial ADT, ng/ml (range) & $0.40(0.01-352)$ & $0.32(0.01-84.7)$ & $0.81(0.01-352)$ & 0.458 \\
\hline Median time to PSA nadir during initial & $200(18-4,894)$ & $204(19-4,894)$ & $164(18-333)$ & 0.158 \\
\hline \multicolumn{5}{|l|}{ ADT, days (range) } \\
\hline Number of regimens of anti-androgenic agent & & & & 0.114 \\
\hline$\leq 1, \mathrm{n}$ & 26 & 19 & 7 & \\
\hline$\geq 2, \mathrm{n}$ & 67 & 59 & 8 & \\
\hline Previous use of estrogen preparations & & & & 0.017 \\
\hline Yes, $\mathrm{n}$ & 3 & 21 & 9 & \\
\hline No, $n$ & 63 & 57 & 6 & \\
\hline Previous use of ENZ & & & & $<0.001$ \\
\hline Yes, $\mathrm{n}$ & 33 & 21 & 12 & \\
\hline No, $n$ & 60 & 57 & 3 & \\
\hline Bone metastasis & & & & 0.032 \\
\hline Positive, $\mathrm{n}$ & 63 & 49 & 14 & \\
\hline Negative, $\mathrm{n}$ & 30 & 29 & 1 & \\
\hline Lymph node metastasis & & & & 1.000 \\
\hline Positive, $\mathrm{n}$ & 17 & 14 & 3 & \\
\hline Negative, $\mathrm{n}$ & 76 & 64 & 12 & \\
\hline Visceral metastasis & & & & 0.661 \\
\hline Positive, $\mathrm{n}$ & 10 & 8 & 2 & \\
\hline Negative, $\mathrm{n}$ & 83 & 70 & 13 & \\
\hline $\begin{array}{l}\text { Median baseline PSA prior to treatment } \\
\text { with AA, ng/ml (range) }\end{array}$ & $9.86(0.06-853.2)$ & $8.52(0.06-853.2)$ & $25.10(0.40-743.7)$ & 0.197 \\
\hline
\end{tabular}

DTX, docetaxel; iPSA, initial prostate-specific antigen; PSA, prostate-specific antigen; CRPC, castration-resistant prostate cancer; ADT, androgen deprivation therapy; ENZ, enzalutamide; AA, abiraterone acetate.

that in the post-DTX group (47 vs. 20\%). In the DTX-naïve group, the PSA response rate to AA in the pre-ENZ group was higher to that that in the post-ENZ group (58 vs. 19\%). In addition, the PSA response rate to AA in non-mCRPC and mCRPC groups were similar (43 vs. 49\%).

PFS during AA treatment and OS. Median PFS in the DTX-naïve and post-DTX groups were 171 (95\% CI, 126-308) and 56 (95\% CI, 21-99) days, respectively. PFS in the DTX-naïve group was significantly longer compared with that in the post-DTX group ( $\mathrm{P}=0.001$; Fig. $2 \mathrm{~A})$. The DTX-naïve group did not reach the median OS [95\% CI, 478-not applicable (NA) days]. Note that in the Kaplan-Meier method, if OS is $>50 \%$ at the last time point, then median OS is not defined and has 'not been reached'. A survival curve must reach the point at which $50 \%$ of patients have died for a median OS to be defined. The median OS in the post-DTX group was 761 days (95\% CI, 407-2,146 days), and there was no significant difference in OS between the DTX-naïve and post-DTX groups $(\mathrm{P}=0.954$; Fig. 2B). In the DTX-naïve group, the median PFS in the pre- and post-ENZ groups were 278 (95\% CI, 112-392) 

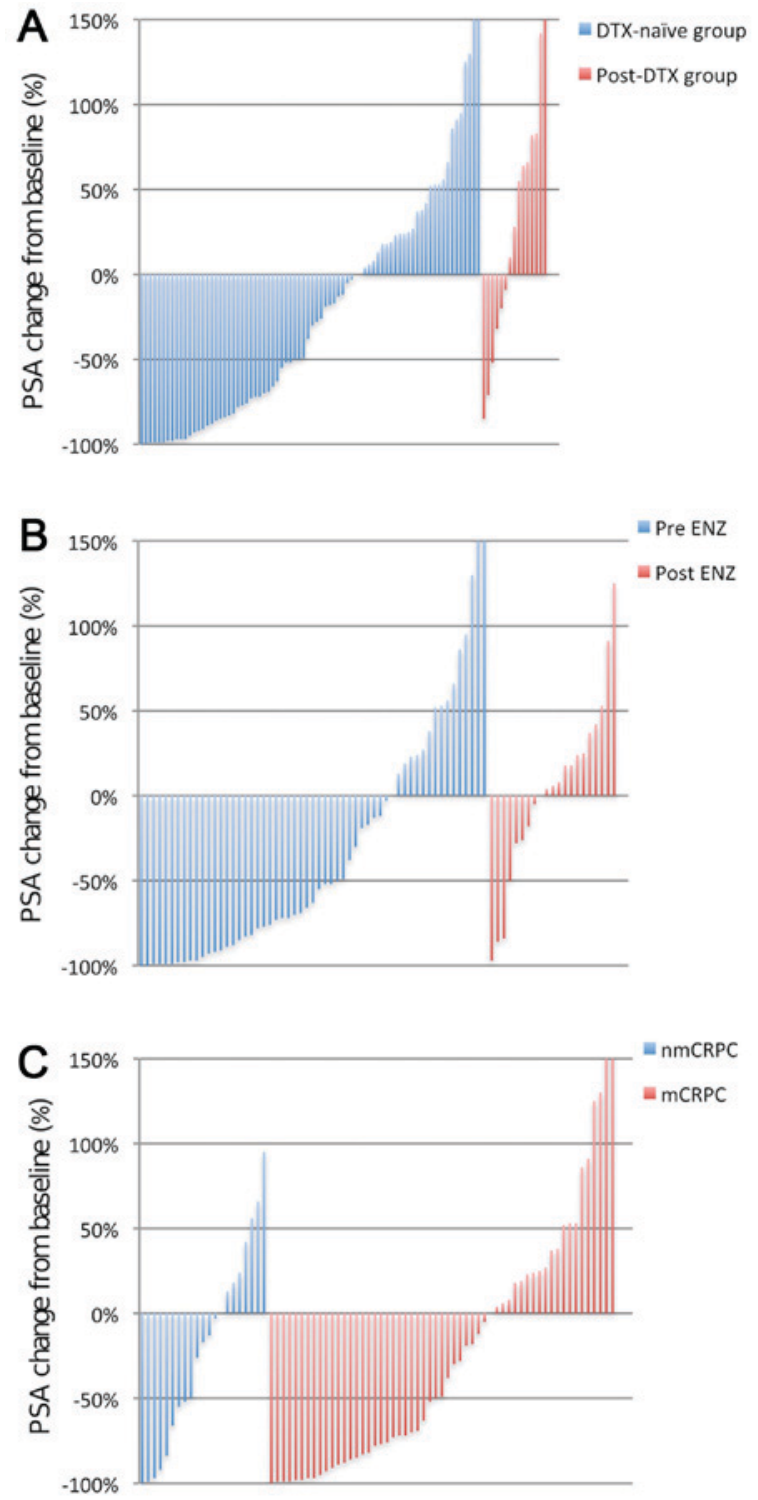

Figure 1. Waterfall plots presenting the response in terms of changes in PSA levels from the baseline in chemo-naïve patients treated with abiraterone acetate. (A) DTX-naïve and post-DTX groups. (B) Pre-ENZ and post-ENZ groups. (C) nmCRPC and mCRPC groups. PSA, prostate-specific antigen; DTX, docetaxel; ENZ, enzalutamide; nmCRPC, non-metastatic castration-resistant prostate cancer; mCRPC, metastatic castration-resistant prostate cancer.

and 168 (95\% CI, 81-310) days, respectively, with no significant difference between them ( $\mathrm{P}=0.355$; Fig. $3 \mathrm{~A})$. The median $\mathrm{OS}$ in the pre-ENZ group was 515 (95\% CI, 372-NA). The post-ENZ cohort did not reach the median OS (95\% CI, 469-NA days; Fig. 3B), as described above. There was no significant difference in OS between the pre- and post-ENZ groups $(\mathrm{P}=0.103$; Fig. 3B). Furthermore, the median PFS in the nmCRPC and mCRPC groups were 511 (95\% CI, 81-NA) and 171 (95\% CI, 126-294) days, respectively, with no significance between them ( $\mathrm{P}=0.489$; Fig. 4A). The median OS in the nmCRPC group was 515 (95\% CI, 360-NA). The mCRPC cohort did not reach the median OS (95\% CI, 469-NA days). There was no significant difference in OS between the nmCRPC and mCRPC groups $(\mathrm{P}=0.299$; Fig. 4B). Due to the small number of patients that succumbed to disease, the DTX-naïve, post-ENZ and mCRPC cohorts did not reach the median OS, for the reason described above.

Prognostic factors for PFS and OS. Univariate analysis using a Cox proportional hazards model revealed that the previous use of estrogen preparations $(\mathrm{P}<0.001 ; \mathrm{HR}, 0.363 ; 95 \% \mathrm{CI}$, 0.210-0.629), previous use of ENZ ( $\mathrm{P}=0.019$; HR, 1.892; 95\% CI, 1.106-3.236) and previous use of docetaxel $(\mathrm{P}=0.002$; HR, 0.381; 95\% CI, 0.206-0.702) were significant determinants of PFS, compared with no previous treatment. Additionally, PSA response compared with no response $(\mathrm{P}<0.001$; HR, 7.224; 95\% CI, 3.583-14.56) and a $<10 \mathrm{ng} / \mathrm{ml}$ baseline PSA compared with a $\geq 10 \mathrm{ng} / \mathrm{ml}$ baseline PSA prior to treatment with AA ( $\mathrm{P}<0.001$; HR, 0.306; 95\% CI, 0.171-0.547) were significant determinants of PFS (Table II). In multivariate analysis, a PSA response compared with no response $(\mathrm{P}<0.001$; HR, 6.085; 95\% CI, 3.071-12.060) and a $<10 \mathrm{ng} / \mathrm{ml}$ baseline PSA compared with a $\geq 10 \mathrm{ng} / \mathrm{ml}$ baseline PSA prior to treatment with AA ( $\mathrm{P}=0.001$; HR, 0.369; 95\% CI, 0.205-0.663) were significant determinants of PFS (Table II). For OS, univariate analysis identified previous use of estrogen preparations compared with no use $(\mathrm{P}=0.027$; HR, $0.409 ; 95 \% \mathrm{CI}$, 0.186-0.902) and a $<10 \mathrm{ng} / \mathrm{ml}$ baseline PSA compared with a $\geq 10 \mathrm{ng} / \mathrm{ml}$ baseline PSA prior to treatment with AA ( $\mathrm{P}=0.024$; HR, 0.385; 95\% CI, 0.167-0.883) as significant determinants of OS. In multivariate analysis, $<10 \mathrm{ng} / \mathrm{ml}$ baseline PSA, compared with a $\geq 10 \mathrm{ng} / \mathrm{ml}$ baseline PSA, prior to treatment with AA ( $\mathrm{P}=0.024 ; \mathrm{HR}, 0.385 ; 95 \% \mathrm{CI}, 0.167-0.883)$ was the only independent significant predictor of OS (Table III).

\section{Discussion}

In the present retrospective multicenter study, the PSA response rate, PFS and OS were examined in DTX-naïve and post-DTX patients with CRPC and in pre- and post-ENZ patients with DTX-naïve CRPC. In the patients of the present study, $47 \%$ of DTX-naïve patients exhibited a 50\% decrease in PSA. The PFS in all DTX-naïve patients was 171 days and OS did not reach the median. In the COU-AA-302 clinical trial (7), 68\% of all patients demonstrated a 50\% PSA decline; additionally, the median biochemical PFS was 11.1 months and the OS was 34.7 months. The clinical efficacy and PSA response rate in the DTX-naïve patients in the present study was similar to that in the COU-AA-302 clinical trial (7); however, the OS and PFS were markedly shorter in the present cohort. The poorer outcomes may be due to the higher proportion of patients that underwent treatment with an anti-androgen regimen and had a history of estramustine phosphate or ENZ use. In addition, the DTX-naïve patients in the present study included cases with visceral disease, which were excluded in the COU-AA-302 clinical trial (7).

In post-DTX patients, $20 \%$ of patients exhibited a $50 \%$ PSA decline; in these patients, the median PFS was 56 days and the median OS was 761 days. Of the patients in the COU-AA-301 clinical trial (6), 29\% of all patients exhibited a 50\% decline in PSA levels; in these patients, the median biochemical PFS was 8.5 months and the OS was 15.8 months. OS could not be compared between the two studies owing to the difference in start dates; however, PFS in the post-DTX patients group in the present study appeared to be shorter than that in the 

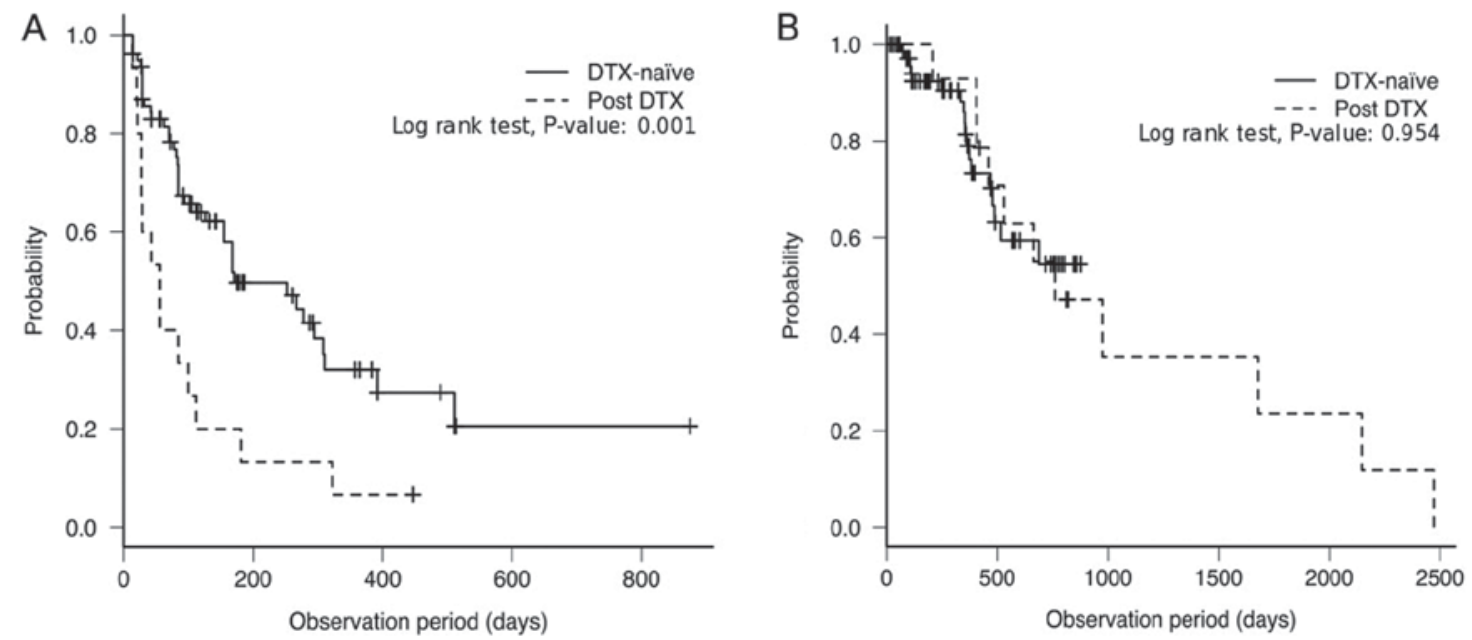

Figure 2. Survival of DTX-naïve patients and post-DTX patients treated with AA. (A) Progression-free survival and (B) overall survival in DTX-naïve patients and post-DTX patients treated with AA. DTX, docetaxel; AA, abiraterone acetate.
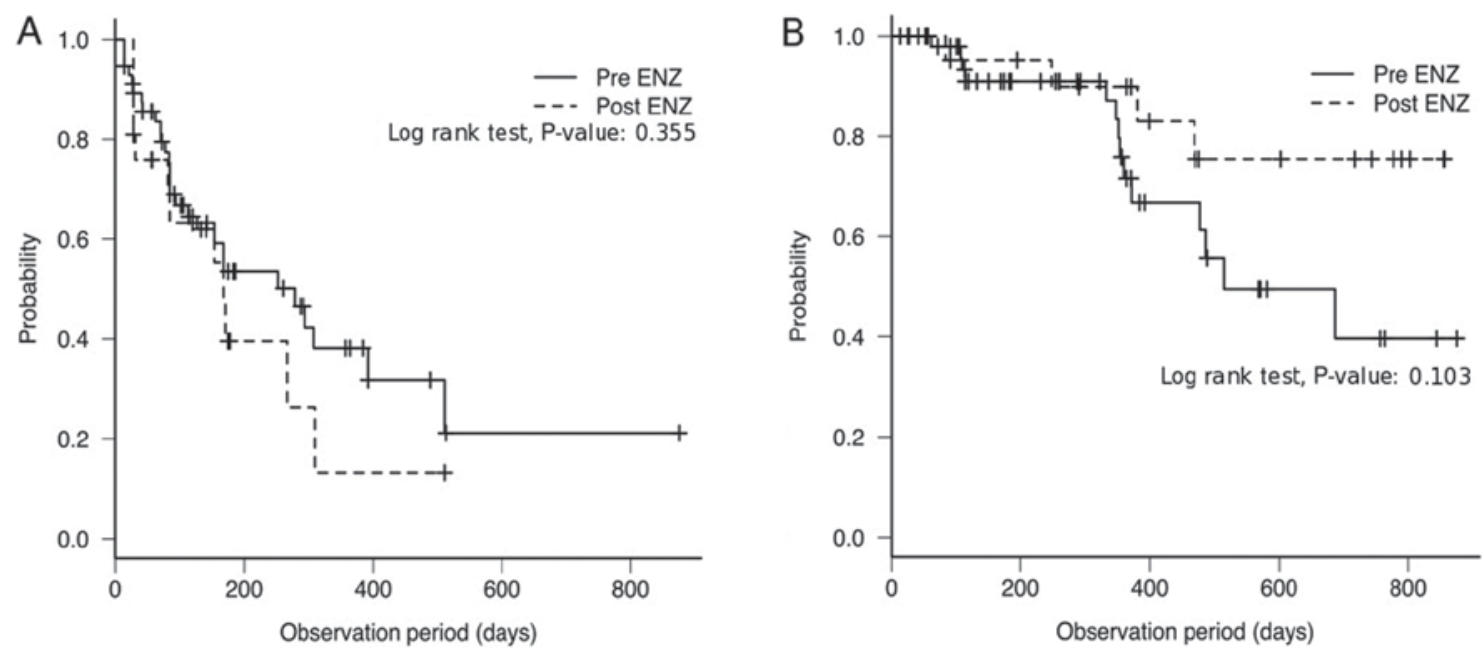

Figure 3. Survival of pre-ENZ patients and post-ENZ patients treated with AA prior to DTX therapy. (A) Progression-free survival in pre-ENZ patients and post-ENZ patients treated with AA prior to DTX therapy. (B) Overall survival in pre-ENZ patients and post-ENZ patients treated with AA prior to DTX therapy. AA, abiraterone acetate; ENZ, enzalutamide; DTX, docetaxel.
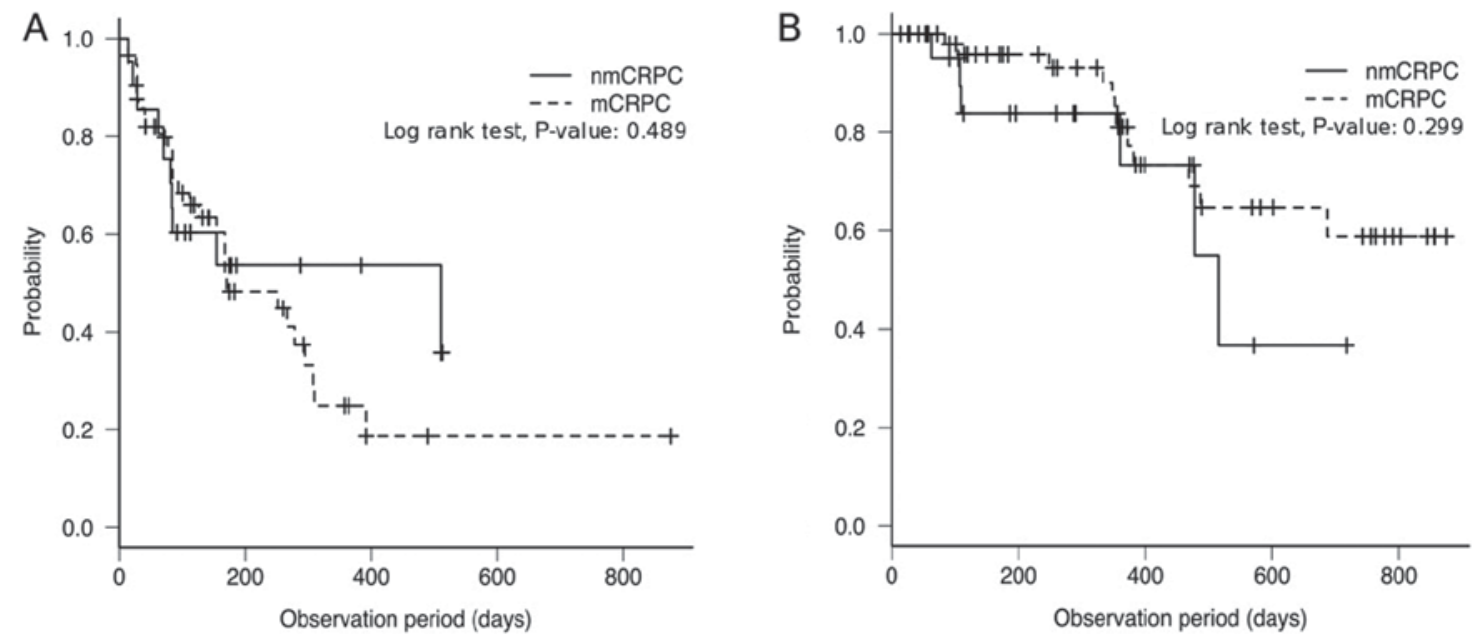

Figure 4. Survival of nmCRPC patients and mCRPC patients treated with AA prior to DTX therapy. (A) Progression-free survival in nmCRPC patients and mCRPC patients treated with AA prior to DTX therapy. (B) Overall survival in nmCRPC patients and mCRPC patients treated with AA prior to DTX therapy. AA, abiraterone acetate; DTX, docetaxel; nmCRPC, nonmetastatic castration-resistant prostate cancer; mCRPC, metastatic castration-resistant prostate cancer. 
Table II. Univariate and multivariate analysis for progression-free survival.

\begin{tabular}{|c|c|c|c|c|c|}
\hline \multirow[b]{2}{*}{ Clinicopathological characteristics } & \multirow[b]{2}{*}{ Compared groups } & \multicolumn{2}{|c|}{ Univariate analysis } & \multicolumn{2}{|c|}{ Multivariate analysis } \\
\hline & & HR $(95 \%$ CI $)$ & P-value & HR $(95 \%$ CI $)$ & P-value \\
\hline Age, years & $<75$ vs. $\geq 75$ & $1.12(0.65-1.96)$ & 0.679 & & \\
\hline Gleason score & $\leq 8$ vs. $\geq 9$ & $0.69(0.39-1.27)$ & 0.233 & & \\
\hline Prostatectomy or radiation & Yes vs. no & $1.65(0.82-3.34)$ & 0.162 & & \\
\hline iPSA, ng/ml & $<150$ vs. $\geq 150$ & $0.90(0.52-1.57)$ & 0.717 & & \\
\hline Time to CRPC, days & $<600$ vs. $\geq 600$ & $1.17(0.67-2.03)$ & 0.582 & & \\
\hline PSA nadir, ng/ml & $<0.5$ vs. $\geq 0.5$ & $0.60(0.34-1.07)$ & 0.082 & & \\
\hline Period from initial ADT start to PSA nadir, days & $<300$ vs. $\geq 300$ & $1.32(0.74-2.35)$ & 0.342 & & \\
\hline Number of antiandrogen treatment lines & $\leq 1$ vs. $\geq 2$ & $1.24(0.68-2.26)$ & 0.481 & & \\
\hline Previous use of estrogen preparations & Yes vs. no & $0.36(0.21-0.63)$ & $<0.001$ & $0.58(0.32-1.05)$ & 0.073 \\
\hline Bone metastasis & Yes vs. no & $0.53(0.28-1.00)$ & 0.049 & & \\
\hline Lymph node metastasis & Yes vs. no & $0.73(0.39-1.36)$ & 0.314 & & \\
\hline Visceral metastasis & Yes vs. no & $0.76(0.34-1.69)$ & 0.501 & & \\
\hline Previous use of ENZ & Yes vs. no & $1.89(1.10-3.24)$ & 0.019 & $0.86(0.47-1.59)$ & 0.635 \\
\hline Previous use of DTX & Yes vs. no & $0.38(0.21-0.70)$ & 0.002 & $1.12(0.44-2.89)$ & 0.802 \\
\hline Baseline PSA prior to treatment with AA, ng/ml & $<10$ vs. $\geq 10$ & $0.30(0.17-0.55)$ & $<0.001$ & $0.37(0.21-0.66)$ & 0.001 \\
\hline PSA response $(\%)$ & Yes vs. no & $7.22(3.58-14.6)$ & $<0.001$ & $6.09(3.07-12.0)$ & $<0.001$ \\
\hline
\end{tabular}

iPSA, initial prostate-specific antigen; CRPC, castration-resistant prostate cancer; ADT, androgen deprivation therapy; ENZ, enzalutamide; DTX, docetaxel; AA, abiraterone acetate; HR, hazard ratio; CI, confidence interval.

Table III. Univariate and multivariate analysis for overall survival.

\begin{tabular}{|c|c|c|c|c|c|}
\hline \multirow[b]{2}{*}{ Clinicopathological characteristics } & \multirow[b]{2}{*}{ Compared groups } & \multicolumn{2}{|c|}{ Univariate analysis } & \multicolumn{2}{|c|}{ Multivariate analysis } \\
\hline & & $\mathrm{HR}(95 \% \mathrm{CI})$ & P-value & $\operatorname{HR}(95 \% \mathrm{CI})$ & P-value \\
\hline Age, years & $<75$ vs. $\geq 75$ & $1.25(0.55-2.86)$ & 0.597 & & \\
\hline Gleason score & $\leq 8$ vs. $\geq 9$ & $0.78(0.34-1.77)$ & 0.500 & & \\
\hline Prostatectomy or radiation & Yes vs. no & $1.08(0.43-2.70)$ & 0.547 & & \\
\hline iPSA, ng/ml & $<150$ vs. $\geq 150$ & $0.85(0.38-1.89)$ & 0.691 & & \\
\hline Time to CRPC, days & $<600$ vs. $\geq 600$ & $1.27(0.59-2.73)$ & 0.534 & & \\
\hline PSA nadir, ng/ml & $<0.5$ vs. $\geq 0.5$ & $1.28(0.56-2.91)$ & 0.554 & & \\
\hline Period from initial ADT start to PSA nadir, days & $<300$ vs. $\geq 300$ & $2.43(0.99-5.99)$ & 0.053 & & \\
\hline Number of anti-androgen treatment lines & $\leq 1$ vs. $\geq 2$ & $1.29(0.58-2.88)$ & 0.532 & & \\
\hline Previous use of estrogen preparations & Yes vs. no & $0.41(0.19-0.90)$ & 0.027 & $0.5(0.22-1.14)$ & 0.097 \\
\hline Bone metastasis & Yes vs. no & $1.05(0.44-2.53)$ & 0.915 & & \\
\hline Lymph node metastasis & Yes vs. no & $1.28(0.51-3.22)$ & 0.603 & & \\
\hline Visceral metastasis & Yes vs. no & $0.58(0.22-1.55)$ & 0.278 & & \\
\hline Previous use of ENZ & Yes vs. no & $0.53(0.24-1.19)$ & 0.125 & & \\
\hline Previous use of DTX & Yes vs. no & $1.03(0.42-2.50)$ & 0.954 & & \\
\hline Baseline PSA prior to treatment with $\mathrm{AA}, \mathrm{ng} / \mathrm{ml}$ & $<10$ vs. $\geq 10$ & $0.38(0.17-0.88)$ & 0.024 & $0.38(0.17-0.88)$ & 0.024 \\
\hline
\end{tabular}

iPSA, initial prostate-specific antigen; CRPC, castration-resistant prostate cancer; ADT, androgen deprivation therapy; ENZ, enzalutamide; DTX, docetaxel; AA, abiraterone acetate; HR, hazard ratio; CI, confidence interval.

COU-AA-301 clinical trial (6). This may also be due to the higher proportion of patients with a high Gleason score and a history of ENZ use. A number of previous studies in Japanese patients with CRPC have also revealed a shorter PFS and OS compared with those in phase III trials (20-22). It has been reported that the differences in androgen receptor signaling 
between men of African and Caucasian descent accounts for the differences in the percentage of patients responding to AA, using the decline in PSA level as a marker of responsiveness, although there were no significant differences in PFS or OS (13). Similarly, it may be that the response in Japanese patients may also differ.

The AR-signaling pathway is a target common to ENZ and AA; however, these drugs differ in their mechanism of action. ENZ inhibits AR signaling by the competitive inhibition of binding of androgens, which inhibits the translocation of the ligand-bound receptor to the nucleus and the subsequent binding to its response elements in DNA. By contrast, AA inhibits CYP17A1, which is crucial for testosterone synthesis, resulting in the potent suppression of extragonadal androgen production $(6,8)$. The specific mechanisms of resistance to ENZ and AA have yet to be clearly identified. However, Antonarakis et al (23) revealed that the detection of androgen receptor splice variant-7 (AR-V7) mRNA in circulating tumor cells was associated with poorer outcomes in patients with CRPC treated with AA and ENZ. Additionally, prior treatment with ENZ and AA is associated with AR-V7 positivity, and thus AR-V7 may be linked to cross-resistance (23).

The outcome of AA treatment in DTX-naïve patients with CRPC following progression during ENZ treatment is unknown. In a study of outcomes of AA following the failure of ENZ in 14 DTX-naïve patients with mCRPC, Yamada et al (24) revealed a 50\% PSA decline rate of $7 \%$, median PFS of 3.4 months and median OS from the initial treatment of AA of 9.1 months. Miyake et al (22) compared the efficacies of sequential AA and ENZ therapy in patients with DTX-naïve mCRPC. In 59 patients receiving AA therapy following progression after treatment with ENZ, the $50 \%$ PSA decline rate was $16.9 \%$, median PFS was 2.6 months and median OS from the initial treatment of ENZ was 22.1 months. There are also a number of reports on AA in post-DTX patients with CRPC following progression after treatment with ENZ $(25,26)$. In 30 post-DTX patients treated with AA following the failure of ENZ therapy, Noonan et al (25) identified that $4 \%$ of all patients had a $50 \%$ PSA decline after treatment with AA, median PFS of 15.4 weeks and median OS from the initial treatment of AA of 50.1 weeks. In a similar study, in 38 post-DTX patients treated with AA following progression after treatment with ENZ, the $8 \%$ of all patients had a $50 \%$ PSA decline after treatment with AA the median PFS was 2.7 months and the median OS from the initiation of AA treatment was 7.2 months (26). Regardless of the history of DTX treatment, these outcomes in post-ENZ patients were inferior to those of pre-ENZ patients owing to the cross-resistance between ENZ and AA therapies.

The group of patients who comprised the present study population contains patients with CRPC, according to their PSA levels, without radiological evidence of metastasis. The provisional clinical opinion of the American Society of Clinical Oncology differs on its consensus recommendations for treatment, as in men with CRPC displaying no evidence of metastasis, second-line hormonal therapy in those in the high risk group may be considered but is not advised (27). In patients with metastatic cancer, AA or ENZ is advised. A majority of clinical studies on AA concern patients with
mCRPC; however, it was previously reported that treatment with ADT in combination with AA was associated with significantly higher rates of OS and PFS compared with ADT alone in men with castration-sensitive PC $(28,29)$. Although no difference was observed between patients with nmCRPC and patients with $\mathrm{mCRPC}$ in the present study owing to the limited number of patients, AA may be more effective for patients with nmCRPC compared with patients with mCRPC based on previous evidence.

The Eastern Cooperative Oncology Group performance status (ECOG-PS), duration of ADT, PSA response and presence of visceral metastasis have been reported to be prognostic factors for patients with $\mathrm{mCRPC}$ receiving AA treatment (30-32). In a study of 220 post-DTX patients treated with AA, Van Praet et al (33) obtained an improved estimate of OS using a multivariate model comprising 5 independent risk factors: Hemoglobin $<12 \mathrm{~g} / \mathrm{dl},>10$ metastases, ECOG-PS, radiographic progression and $<90$ months since diagnosis. However, the majority of studies have focused on post-DTX patients and there are few reliable prognostic models in DTX-naïve patients with CRPC treated with AA. Poon et al (34) suggested that visceral metastasis and the response of PSA were associated with PFS and OS in 58 DTX-naïve patients with $\mathrm{mCRPC}$ treated with AA, similar to post-DTX patients with mCRPC. In addition, Miyake et al (35) revealed that the time until PSA nadir following treatment with AA was an independent predictor of PFS in 125 patients with DTX-naïve mCRPC receiving AA. In a study that included DTX-naïve and post-DTX patients with CRPC, 'duration of primary ADT' and 'no prior chemotherapy' were associated with the duration of AA treatment (36).

The present study revealed that a history of anti-CRPC agent use, including DTX and ENZ, was associated with PFS time in univariate analysis. In the present study, the response to ENZ, DTX and estrogen preparations that were previously performed were not assessed; however, they may be associated with the therapeutic effect of AA.

The response of PSA was significantly associated with PFS in multivariate analysis. In the exploratory analysis of the COU-AA-302 clinical trial, the association of PSA response with radiographic PFS (rPFS), OS time and time to PSA progression was examined. Another study has revealed the presence of an association between PSA response and treatment efficacy of AA (37). Additionally, Rescigno et al (38) identified that patients that did not achieve a $30 \%$ decline in PSA after 4 weeks of AA had a lower likelihood of achieving a PSA response at 12 weeks and a significantly decreased OS time, compared with patients that achieve a $30 \%$ decline in a study of 274 patients with mCRPC treated with AA prior to or following DTX treatment. If a PSA response is associated with PFS or OS time, it may be an effective clinical biomarker. However, a PSA flare, a phenomenon in which PSA is temporarily elevated following the treatment of an luteinizing-hormone-releasing hormone agonist or DTX treatment, may also occur with AA treatment (39). Therefore, when observing changes in PSA, the possibility of PSA flares should be considered. The baseline PSA level prior to treatment with AA was the only independent prognostic factor for PFS and OS in the present study. In the exploratory analysis of the COU-AA-302 clinical trial, associations were 
identified between baseline PSA level and rPFS, OS and time until PSA progression, including the PSA response (37). These results indicate that long-term treatment efficacy may be sustained by the administration of AA when PSA levels are low.

There are several limitations in the present study. PFS was not analyzed separately for PSA and rPFS, and the limited sample size prevented separate analyses for DTX-naive and post-DTX patients. In addition, owing to the short observation period, the median OS time was not reached for DTX-naive patients. Furthermore, the group of patients that comprised the study population was not representative of a typical patient with prostate cancer who has failed treatment following primary curative therapy, which is due to the fact that few patients in the present study underwent prior prostatectomy radical or radiotherapy, and at least two-thirds of patients had a Gleason score of at least 9. The PSA level at the time of diagnosis was a median of $92 \mathrm{ng} / \mathrm{ml}$, which does not correspond to a typical screening population with PSA of $>4 \mathrm{ng} / \mathrm{ml}$. Thus, the study group appears to have a selection bias towards high-grade cancer. Despite quality-control efforts, the study is additionally limited by its retrospective design, potential for selection bias and incomplete or variable assessments. However the results of the present study reflect the characteristics of AA treatment of CRPC in current clinical practice in Japan.

In conclusion, the present study evaluated the outcomes of patients with CRPC treated with AA in clinical practice in Japan. The efficacy of AA appeared to be lower in the present cohort than that in other studies, which may be due to a higher proportion of patients with a high Gleason score, treatment with an anti-androgen regimen, and a history of estramustine phosphate or ENZ use in the present study. Analysis of prognostic factors revealed that PSA response and baseline PSA levels were associated with a longer PFS time and baseline PSA was associated with longer OS time. In this context, long-term treatment efficacy may be sustained by the administration of AA in patients with lower PSA levels, and it may be better to change the agent at an early stage if patients do not exhibit a response as measured by PSA levels.

\section{References}

1. Huggins $\mathrm{C}$ and Hodges CV: Studies on prostatic cancer. I. The effect of castration, of estrogen and androgen injection on serum phosphatases in metastatic carcinoma of the prostate. CA Cancer J Clin 22: 232-240, 1972.

2. Walczak JR and Carducci MA: Prostate cancer: A practical approach to current management of recurrent disease. Mayo Clin Proc 82: 243-249, 2007.

3. Chi KN, Bjartell A, Dearnaley D, Saad F, Schröder FH, Sternberg C, Tombal B and Visakorpi T: Castration-resistant prostate cancer: From new pathophysiology to new treatment targets. Eur Urol 56: 594-605, 2009.

4. Berthold DR, Pond GR, Soban F, de Wit R, Eisenberger M and Tannock IF: Docetaxel plus prednisone or mitoxantrone plus prednisone for advanced prostate cancer: Updated survival in the TAX 327 study. J Clin Oncol 26 242-245, 2008.

5. Seruga B, Ocana A and Tannock IF: Drug resistance in metastatic castration-resistant prostate cancer. Nat Rev Clin Oncol 8 : 12-23, 2011.

6. de Bono JS, Logothetis CJ, Molina A, Fizazi K, North S, Chu L, Chi KN, Jones RJ, Goodman OB Jr, Saad F, et al: Abiraterone and increased survival in metastatic prostate cancer. N Engl J Med 364: 1995-2005, 2011.
7. Ryan CJ, Smith MR, de Bono JS, Molina A, Logothetis CJ, de Souza P, Fizazi K, Mainwaring P, Piulats JM, Ng S, et al: Abiraterone in metastatic prostate cancer without previous chemotherapy. N Engl J Med 368: 138-148, 2013.

8. Scher HI, Fizazi K, Saad F, Taplin ME, Sternberg CN, Miller K, de Wit R, Mulders P, Chi KN, Shore ND, et al: Increased survival with enzalutamide in prostate cancer after chemotherapy. N Engl J Med 367: 1187-1197, 2012.

9. Beer TM, Armstrong AJ, Rathkopf DE, Loriot Y, Sternberg CN, Higano CS, Iversen P, Bhattacharya S, Carles J, Chowdhury S, et al: Enzalutamide in metastatic prostate cancer before chemotherapy. N Engl J Med 371: 424-433, 2014.

10. de Bono JS, Oudard S, Ozguroglu M, Hansen S, Machiels JP, Kocak I, Gravis G, Bodrogi I, Mackenzie MJ, Shen L, et al: Prednisone plus cabazitaxel or mitoxantrone for metastatic castration-resistant prostate cancer progressing after docetaxel treatment: A randomised open-label trial. Lancet 376: 1147-1154, 2010.

11. Attard G, Belldegrun AS and de Bono JS: Selective blockade of androgenic steroid synthesis by novel lyase inhibitors as a therapeutic strategy for treating metastatic prostate cancer. BJU Int 96: 1241-1246, 2005.

12. Yamasaki M, Yuasa T, Yamamoto S, Hayashi T, Ogawa M, Sakura M, Masuda H, Fukui I and Yonese J: Efficacy and safety profile of enzalutamide for Japanese patients with castration-resistant prostate cancer. Anticancer Res 36: 361-365, 2016.

13. Ramalingam S, Humeniuk MS, Hu R, Rasmussen J, Healy P, Wu Y, Harrison MR, Armstrong AJ, George DJ and Zhang T: Prostate-specific antigen response in black and white patients treated with abiraterone acetate for metastatic castrate-resistant prostate cancer. Urol Oncol 35: 418-424, 2017.

14. Mezynski J, Pezaro C, Bianchini D, Zivi A, Sandhu S, Thompson E, Hunt J, Sheridan E, Baikady B, Sarvadikar A, et al: Antitumour activity of docetaxel following treatment with the CYP17A1 inhibitor abiraterone: Clinical evidence for cross-resistance? Ann Oncol 23: 2943-2947, 2012.

15. van Soest RJ, Nieuweboer AJ, de Morrée ES, Chitu D, Bergman AM, Goey SH, Bos MM, van der Meer N, Hamberg P, de Wit R and Mathijssen RH: The influence of prior novel androgen receptor targeted therapy on the efficacy of cabazitaxel in men with metastatic castration-resistant prostate cancer. Eur J Cancer 51: 2562-2569, 2015.

16. Scher HI, Halabi S, Tannock I, Morris M, Sternberg CN, Carducci MA, Eisenberger MA, Higano C, Bubley GJ, Dreicer R, et al: Design and end points of clinical trials for patients with progressive prostate cancer and castrate levels of testosterone: Recommendations of the prostate cancer clinical trials working group. J Clin Oncol 26: 1148-1159, 2008.

17. Therasse P, Arbuck SG, Eisenhauer EA, Wanders J, Kaplan RS, Rubinstein L, Verweij J, Van Glabbeke M, van Oosterom AT, Christian MC and Gwyther SG: New guidelines to evaluate the response to treatment in solid tumors. European organization for research and treatment of cancer, National cancer institute of the United States, National cancer institute of Canada. J Natl Cancer Inst 92: 205-216, 2000.

18. Epstein JI, Allsbrook WC Jr, Amin MB, Egevad LL; ISUP Grading Committee: The 2005 international society of urological pathology (ISUP) consensus conference on gleason grading of prostatic carcinoma. Am J Surg Pathol 29: 1228-1242, 2005.

19. Kanda Y: Investigation of the freely available easy-to-use software 'EZR' for medical statistics. Bone Marrow Transplant 48: 452-458, 2013

20. Matsubara N, Uemura H, Satoh T, Suzuki H, Nishiyama T, Uemura $\mathrm{H}$, Hashine K, Imanaka K, Ozono S and Akaza H: A phase 2 trial of abiraterone acetate in Japanese men with metastatic castration-resistant prostate cancer and without prior chemotherapy (JPN-201 study). Jpn J Clin Oncol 44: 1216-1226, 2014.

21. Satoh T, Uemura H, Tanabe K, Nishiyama T, Terai A, Yokomizo A, Nakatani T, Imanaka K, Ozono S and Akaza H: A phase 2 study of abiraterone acetate in Japanese men with metastatic castration-resistant prostate cancer who had received docetaxel-based chemotherapy. Jpn J Clin Oncol 44: 1206-1215, 2014.

22. Miyake H, Hara T, Terakawa T, Ozono S and Fujisawa M: Comparative assessment of clinical outcomes between abiraterone acetate and enzalutamide in patients with docetaxel-naive metastatic castration-resistant prostate cancer: Experience in real-world clinical practice in Japan. Clin Genitourin Cancer 15: 313-319, 2017. 
23. Antonarakis ES, Lu C, Wang H, Luber B, Nakazawa M, Roeser JC, Chen Y, Mohammad TA, Chen Y, Fedor HL, et al: AR-V7 and resistance to enzalutamide and abiraterone in prostate cancer. N Engl J Med 371: 1028-1038, 2014.

24. Yamada Y, Matsubara N, Tabata KI, Satoh T, Kamiya N, Suzuki H, Kawahara T, Uemura H, Yano A and Kawakami S: Abiraterone acetate after progression with enzalutamide in chemotherapy-naïve patients with metastatic castration-resistant prostate cancer: A multi-center retrospective analysis. BMC Res Notes 9: 471, 2016.

25. Noonan KL, North S, Bitting RL, Armstrong AJ, Ellard SL and Chi KN: Clinical activity of abiraterone acetate in patients with metastatic castration-resistant prostate cancer progressing after enzalutamide. Ann Oncol 24: 1802-1807, 2013.

26. Loriot Y, Bianchini D, Ileana E, Sandhu S, Patrikidou A, Pezaro C, Albiges L, Attard G, Fizazi K, De Bono JS and Massard C: Antitumour activity of abiraterone acetate against metastatic castration-resistant prostate cancer progressing after docetaxel and enzalutamide (MDV3100). Ann Oncol 24 1807-1812, 2013

27. Virgo KS, Basch E, Loblaw DA, Oliver TK, Rumble RB, Carducci MA, Nordquist L, Taplin ME, Winquist E and Singer EA: Second line hormonal therapy for men with chemotherapy-Naïve, castration-resistant prostate cancer: American Society of Clinical Oncology provisional clinical opinion. J Clin Oncol 35: 1952-1964, 2017.

28. Fizazi K, Tran N, Fein L, Matsubara N, Rodriguez-Antolin A, Alekseev BY,Özgüroğlu M, Ye D, Feyerabend S, Protheroe A, et al: Abiraterone plus prednisone in metastatic, castration-sensitive prostate cancer. N Engl J Med 377: 352-360, 2017.

29. James ND, de Bono JS, Spears MR, Clarke NW, Mason MD, Dearnaley DP, Ritchie AWS, Amos CL, Gilson C, Jones RJ, et al: Abiraterone for prostate cancer not previously treated with hormone therapy. N Engl J Med 377: 338-351, 2017.

30. Lolli C, Caffo O, Scarpi E, Aieta M, Conteduca V, Maines F Bianchi E, Massari F, Veccia A, Chiuri VE, et al: Systemic immune-inflammation index predicts the clinical outcome in patients with mCRPC treated with abiraterone. Front Pharmacol 7: 376, 2016.

31. Facchini G, Caffo O, Ortega C, D'Aniello C, Di Napoli M, Cecere SC, Della Pepa C, Crispo A, Maines F, Ruatta F, et al: Very early PSA response to abiraterone in MCRPC patients: A novel prognostic factor predicting overall survival. Front Pharmacol 7: 123, 2016

32. Chi KN, Kheoh T, Ryan CJ, Molina A, Bellmunt J, Vogelzang NJ, Rathkopf DE, Fizazi K, Kantoff PW, Li J, et al: A prognostic index model for predicting overall survival in patients with metastatic castration-resistant prostate cancer treated with abiraterone acetate after docetaxel. Ann Oncol 27: 454-460, 2016.
33. Van Praet C, Rottey S, Van Hende F, Pelgrims G, Demey W, Van Aelst F, Wynendaele W, Gil T, Schatteman P, Filleul B, et al: Which factors predict overall survival in patients with metastatic castration-resistant prostate cancer treated with abiraterone acetate post-docetaxel? Clin Genitourin Cancer 15: 502-508, 2017.

34. Poon DM, Chan K, Lee SH, Chan TW, Sze H, Lee EK, Lam D and Chan MF: Abiraterone acetate in metastatic castration-resistant prostate cancer-the unanticipated real-world clinical experience. BMC Urol 16: 12, 2016.

35. Miyake H, Hara T, Tamura K, Sugiyama T, Furuse H, Ozono $\mathrm{S}$ and Fujisawa M: Independent association between time to prostate-specific antigen (PSA) nadir and PSA progression-free survival in patients with docetaxel-naïve, metastatic castration-resistant prostate cancer receiving abiraterone acetate, but not enzalutamide. Urol Oncol 35: 432-437, 2017.

36. McKay RR, Werner L, Fiorillo M, Nakabayashi M, Kantoff PW and Taplin ME: Predictors of duration of abiraterone acetate in men with castration-resistant prostate cancer. Prostate Cancer Prostatic Dis 19: 398-405, 2016.

37. Ryan CJ, Londhe A, Molina A, Smith MR, De bono JS, Mulders P, Rathkopf DE, Saad F, Logothetis C, Fizazi k, et al: Relationship of baseline PSA and degree of PSA decline to radiographic progression-free survival (rPFS) in patients with chemotherapy-naive metastatic castration-resistant prostate cancer (mCRPC): Results from COU-AA-302, J Clin Oncol 31, 2013.

38. Rescigno P, Lorente D, Bianchini D, Ferraldeschi R, Kolinsky MP, Sideris S, Zafeiriou Z, Sumanasuriya S, Smith AD, Mehra N, et al: Prostate-specific antigen decline after 4 weeks of treatment with abiraterone acetate and overall survival in patients with metastatic castration-resistant prostate cancer. Eur Urol 70: 724-731, 2016.

39. Ueda Y, Matsubara N, Tabata KI, Satoh T, Kamiya N, Suzuki H, Kawahara T and Uemura H: Prostate-specific antigen flare phenomenon induced by abiraterone acetate in chemotherapy-naive patients with metastatic castration-resistant prostate cancer. Clin Genitourin Cancer 15: 320-325, 2017.

This work is licensed under a Creative Commons Attribution-NonCommercial-NoDerivatives 4.0 International (CC BY-NC-ND 4.0) License. 